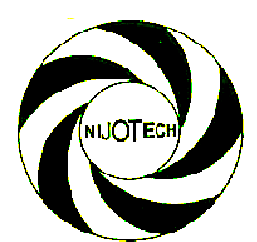

Nigerian Journal of Technology (NIJOTECH)

Vol. 33. No. 1, January 2014, pp. 27 - 32

Copyright@ Faculty of Engineering,

University of Nigeria, Nsukka, ISSN: 111 15-8443

www.nijotech.com

http://dx.doi.org/10.4314/njt.v33i1.4

\title{
APPLICATION OF YIELD LINE THEORY IN PRE-CAST WAFFLE SLAB
}

\author{
J. 0. Akinyele ${ }^{1, *}$, G. A. Alade ${ }^{2}$ \\ 1 Department of Civil Engineering, Federal University of Agriculture, Abeokuta, NigERIA

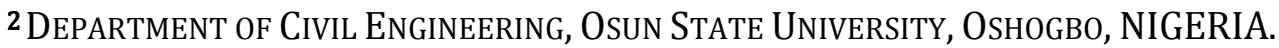

E-mail addresses:1 ${ }^{j o a k i n 777 @ y a h o o . c o m, 2 e n g r a l a d e @ y a h o o . c o . u k ~}$

\begin{abstract}
Analysis of precast waffle slabs have concentrated on the rib portions, while the slab portion were left unanalyzed. This has led to cracks or outright failure of the slab portions due to under reinforcement. This paper proposed the use of yield line theory in solving this problem. Yield line theory was adopted to develop a computer program called YLRGT in the analysis of pre-cast waffle slabs. Three panels with dimensions $6 \mathrm{~m} \times 6 \mathrm{~m}, 6 \mathrm{~m} \times 5 \mathrm{~m}$ and $5 \mathrm{~m} \times 2 \mathrm{~m}$ were analyzed, and the results were compared with an existing analytical method which was based on the BS 8110 slab coefficient factor. YLRGT analyzed the slab portion effectively, unlike the BS 8110 where approximate values were adopted for the slab portion. The paper concluded that the slab portion of pre-cast waffle slabs can be effectively analyzed using the computer program.
\end{abstract}

Keywords: Waffle slabs, Yield line theory, Panels, YLRGT,

\section{Introduction}

Waffle slab has its genesis in a rather thick solidslab floor from which the bottom layer concrete in tension is partially replaced by their ribs along orthogonal directions. The ribs are reinforced with steel to resist flexural tensile stresses. The dimensions and spacing of ribs are decided in a manner so as to achieve better load distribution without requiring the shear reinforcement [1].

Waffle slabs are generally employed in large span slabs, as spans become larger still, the required slab thickness for the flat plate and flat slab increases to the point where the slab may be unable to carry its own weight. A solution to this is to provide thickness so that reinforcement can be placed in a member at greater depth, but remove concrete from regions of the slab not required for strength. It is an extension of the ribbed floor slab in which the slab is ribbed in two directions. Hence, an inverted pot-like hollow is formed which serves as the ceiling for the floor below(Figure 1.). Waffle slabs are all concrete with the inverted pot-like shape formed through the use of a special mould. When compared with the conventional solid flat slab construction, waffle slabs allow a considerable reduction in dead load and can support heavy loads over a long span [2]. It is commonly used in parking garages of tall buildings with ramps and also in industrial facilities and warehouses [3] and meet fire proofing requirements [4] [5]. Also, it has the advantage of medium to long span, light weight, economical in material usage and profiles may be expressed architecturally or used for heat transfer [6]. This slab is usually employed for architectural and structural reasons for large rooms such as auditoria, vestibules, theatre halls, show rooms of shops where column-free-space is often the main requirement [7].

According to Howard and Hansen [8], waffle floors are used extensively in semiconductor factories as they provide high impedance mounts for manufacturing equipment that is extremely vibration sensitive. Also it has been used for cooling towers, storage tanks, communication shelters, barriers and retaining walls, artificial reefs, building walls, hybrid columns and beams [9].

The exact analysis and design of waffle slab is complex, therefore designers adopted simple procedure based on the use of certain coefficients to distribute the load in both directions, with the assumption that the moments on parallel ribs in one direction are equal [10].

In the analysis of waffle slabs, Oyenuga [11] used the coefficient for two-way spanning solid slabs 
in the BS 8110 part 1[12] code. The analysis considered the pot/hollow dimensions of the waffle slabs in which provisions were made for top and bottom reinforcements of the ribs only. Mosley et al [13] designed a waffle slab for a panel in which the ribs were designed as a "T" section. Adequate reinforcements were provided and the deflection of the ribs was also determined. However, there was provision for minimum reinforcements in the slab portion.
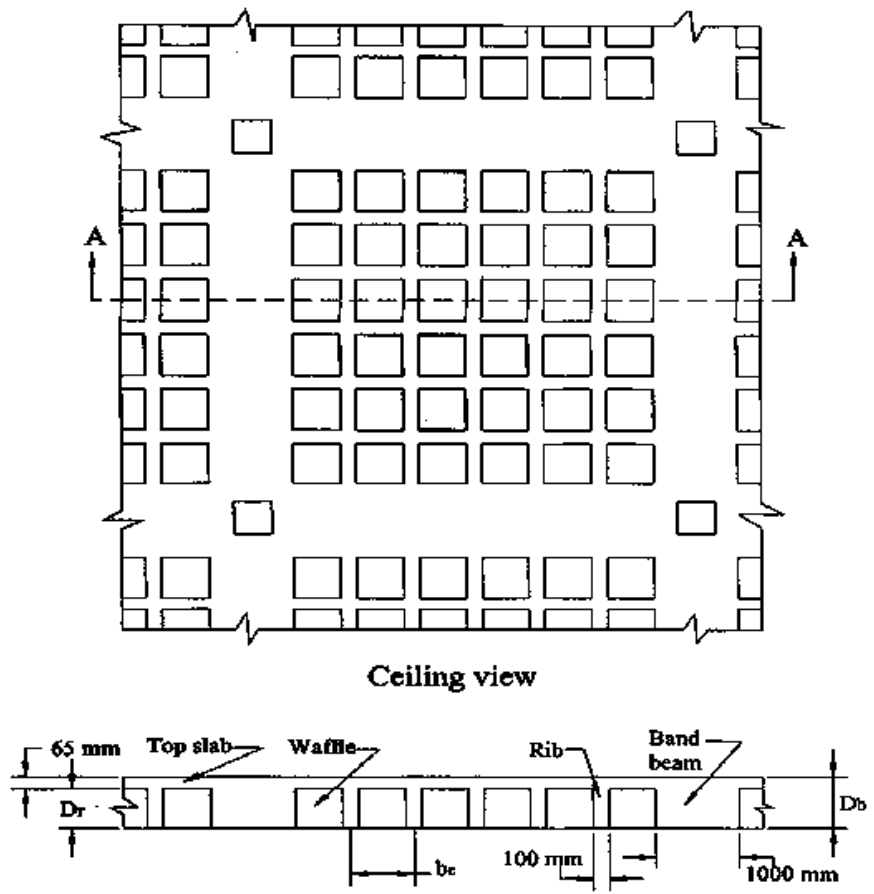

Section A-A

Figure 1: Waffle slab section

Rahman et al [14], used a 3-D strut-and tie model to analyse waffle slab, the thickness of the bottom tie, vertical ties, inclined strut and nodal zones at bottom were taken as the thickness of the waffle ribs. Thickness of the top strut and nodal zones at top was taken as the effective width of top slab and was less than or equal to the rib spacing. It was observed from the work that the ribs were well analysed using the strut- and tie model method, while the slab portion was not analysed. Structural failure in building was attributed to both technical and human errors by Carper [15]. He listed some causes of failure in civil engineering structures to include: programming deficiency, site selection and site development errors, design errors, construction errors, material deficiencies, and operational errors. Of all the causes mentioned, the programming and design errors were the main problems that this study has tried to look at and proffer appropriate solutions.
Yield line design leads to slabs that are quick and easy to handle. The resulting slabs are light and have very low amounts of reinforcement in very regular arrangements. Above all, yield line design generates economic concrete slabs, because it considers failures at the ultimate limit state [16]. Since waffle slab is considered to be economical due to its reduced concrete volume, if compared with solid slabs, Yield line theory will be applied in order to investigate its structural response to loading. The Rankine Grashoff theory of equating deflections at the junctions of ribs is used for the analysis of ribbed or grid floors. The method considers the load in a slab and distributes to all the ribs along both the longitudinal and transverse directions.

In most of the works that have been carried out on waffle slabs, it was only the ribs that were analysed with the provision of adequate reinforcements, but the slab portion has often been left unanalysed. Most designs simply provided wire meshes for the slab portion. Mosley et al [13] simply adopted $12 \%$ of the cross section area of the slab portion as wire mesh reinforcements. However, this method has been found to be adequate for slabs that are cast insitu only, since they are not subjected to the same eccentric forces generated as a result of lifting and transportation of pre-cast waffle slab from the manufacturing plant to the site. In some factories where pre-cast waffle slabs are manufactured using wire mesh in the slab portions, the pre-cast slabs were subjected to both hogging and sagging moments which resulted into cracks and sometimes outright failures during loading and placement.

Considering the problems of pre-cast with wire mesh reinforcements, this study therefore, developed a method (YLRGT) which is based on Yield Line and Rankine Grashoff theories of analysis to provide adequate reinforcements for the precast slab. The yield line will take care of the toping or slab portion that are being presently neglected during analysis, while the Rankine theory will be used to analyse the rib portion of the pre-cast waffle slab.

\section{Sample Properties}

In order to carry out investigation and arrive at a reasonable value, the dimensions for some given pre-cast-waffle slabs of $6 \mathrm{mx} 6 \mathrm{~m}, 6 \mathrm{mx} 5 \mathrm{~m}$ and 5 $\mathrm{m} \times 2 \mathrm{~m}$. were investigated. Keeping the residential and office floors in mind, the general 
thickness adopted was $200 \mathrm{~mm}$; larger spans would require higher floor thickness. The BS 8110 slab coefficient factor was used in the analysis of waffle slab ribs, and the YLRGT which adopted the yield line theory was also used and the two methods were compared. The ribs spacing was $400 \mathrm{~mm}$ while the total depth of waffle slab was $200 \mathrm{~mm}$. The topping was $60 \mathrm{~mm}$ thick, rib depth was $140 \mathrm{~mm}$, and rib width was $100 \mathrm{~mm}$.

The section used was a precast-waffle slab, the characteristic material strengths for concrete and steel were $f_{\mathrm{cu}}=30 \mathrm{~N} / \mathrm{mm}^{2}$ and $f_{\mathrm{y}}=460 \mathrm{~N} / \mathrm{mm}^{2}$ respectively. The moment coefficients were taken from Table 3.14 of BS 8110.

Only gravity loading on the floor has been considered. The live load adopted was $2.5 \mathrm{kN} / \mathrm{m}^{2}$, safety factors for both dead and live loads were applied, and the density of reinforced concrete as $24 \mathrm{kN} / \mathrm{m}^{2}$.

\section{Method of Analysis}

Over time, there have been different analytical methods that have been used in the analysis of waffle slabs. Among these methods are: the orthotropic plate theory, the finite element method, simple frame method, grillage method, the BS 8110 slab coefficient method which is based on the elastic method. This paper has developed a computer-based program that has simplified some of the complex equations in the Yield line theory. The work method which was simplified to standard formulae by Kennedy and Goodchild [16] was adopted in the program. Some of the adopted formulae are shown below. Equation 1 is for a two-way slab supported on all four sides while Equation 2 is for one-way spanning slab. All the equations are for isotropic slabs only; these are slabs with the same amount of reinforcements in both ways.

$$
\begin{aligned}
& m=\frac{n \times a_{r} \times b_{r}}{8\left(1+\frac{b_{r}}{a_{r}}+\frac{a_{r}}{b_{r}}\right)} \\
& m=\frac{n L^{2}}{2\left(\sqrt{1+i_{1}}+\sqrt{1+i_{2}}\right)^{2}}
\end{aligned}
$$

In (1) and (2) $m$ is the the ultimate design moment $(\mathrm{kNm} / \mathrm{m}), \mathrm{n}$ is the the ultimate uniformly distributed load $\left(\mathrm{kN} / \mathrm{m}^{2}\right), \mathrm{L}$ is the length of slab,

$a_{r}$ is the reduced short span dimension, $b_{r}$ is the reduced long span dimension $\left(a_{r}\right.$ and $b_{r}$ are the points of contraflexure along the short and long spans respectively.) while $i$ is the fixity ratio at the supports, i.e, $i_{1}, i_{2}$.For continuous supports, $i_{1}$ $=i_{2}=1$, while for simple supports, $i_{1}=i_{2}=0$.

\subsection{Computer program}

There have been different computer programs that were developed by various researchers and engineers for the analysis of slabs of different shapes and configurations. It has been discovered that most of these programs, except very few, adopted the Finite elements method (FEM) of analysis of structures. The new yield line theory program YLRGT was compared with the BS 8110 1997 slab coefficient method that has been used by many practitioners in the analysis of waffle slabs.

It is possible to analyse all the ribs of a waffle slab using the new program, along both the long and short span of the slab, but it was observed that as the ribs move closer to the edge of the slab, the bending moment obtained reduces, by the time the ribs at the edges are analysed, the bending moment generated will have become so small, hence the maximum bending moment at the mid rib was assumed for other ribs along the same span and any area of reinforcement obtained for the maximum bending moment is also assumed for the other ribs along the same span. The flow chart for the new program (YLRGT) is shown in figure 2 below.

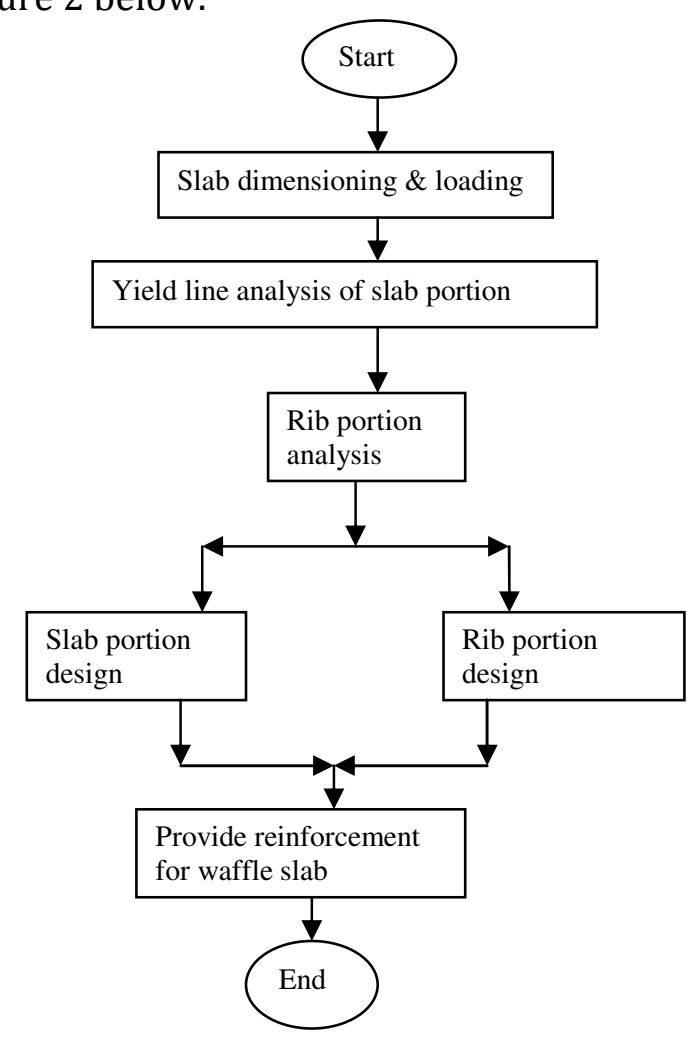

Figure 2: Computer program network diagram 


\section{Results}

The results from Table 1 showed that the YLRGT method was able to analyse the slab portion of the waffle by adopting the yield line theory. The loads were distributed to all the ribs on both axis through the use of the Rankine Grashoff principle, the ribs at the middle carries greater load than those that are toward the edges. This is because deflection and bending moment are high at the middle portions of the slab. The results shown on the table are the maximum load from the mid ribs. The BS 8110 method results showed that the slab portions were not analysed, it is assumed that minimum reinforcement will be provided by adopting $0.12 \mathrm{bh}$ (sectional area) for the toping or slab portion of the waffle slabs.

From the results obtained, it was observed that the BS 8110 gave very low values for the moments generated in the ribs for each direction compared to the result obtained using the YLRGT. The moments obtained were 1.9 times greater than BS 8110 coefficients along the long span, and 2.1 times greater along the short span for the $6 \mathrm{~m} \times 5 \mathrm{~m}$ panel.

For the $6 \mathrm{~m} \times 6 \mathrm{~m}$, the new method has a higher moment of about 1.2 time that of the slab coefficient method for both long and short ribs while the result for the $5 \mathrm{~m} \times 2 \mathrm{~m}$ panel was different from the two previous panels, the BS 8110 slab coefficient method gave a moment that is about 3.3 times that of YLRGT, this was as a results of the panel being a one-way panel, since Yield line method generally generate conservative results in one-way panels, hence the difference.

Table1: Comparison of the bending moment of YLRGT and BS 8110

\begin{tabular}{ccccccc}
\hline Panels & \multicolumn{3}{c}{ YLRGT (kNm) } & \multicolumn{3}{c}{ BS 8110 (kNm) } \\
\hline & SP & L. Rib & S. Rib & SP & L. Rib & S. Rib \\
$6 \mathrm{~m} \times 6 \mathrm{~m}$ & 9.279 & 5.808 & 5.808 & - & 4.897 & 4.897 \\
$6 \mathrm{~m} \times 5 \mathrm{~m}$ & 7.962 & 6.583 & 9.480 & - & 3.46 & 4.560 \\
$5 \mathrm{~m} \times 2 \mathrm{~m}$ & 9.925 & 0.370 & 2.310 & - & - & 7.658 \\
\hline
\end{tabular}

Table 2: Area of reinforcement required for waffle slab

\begin{tabular}{ccccccc}
\hline Panels & \multicolumn{4}{c}{ YLRGT $\left(\mathrm{mm}^{2}\right)$} & \multicolumn{3}{c}{ BS 8110 $\left(\mathrm{mm}^{2}\right)$} \\
& SP & L. & S. Rib & SP & L.Rib & S. Rib \\
& & Rib & & & & \\
$6 \mathrm{~m} \times 6 \mathrm{~m}$ & 771 & 136 & 136 & 72 & 89 & 89 \\
$6 \mathrm{~m} \times 5 \mathrm{~m}$ & 479 & 147 & 238 & 72 & 49 & 65 \\
$5 \mathrm{~m} \times 2 \mathrm{~m}$ & 553 & 10 & 179 & 72 & - & 153 \\
\hline
\end{tabular}
rib of waffle, S. Rib is the Short rib of waffle, $6 \mathrm{mx}$ $6 \mathrm{~m}$ and $6 \mathrm{~m} \times 5 \mathrm{~m}$ are two way slabs, while $5 \mathrm{~m} \mathrm{x}$ $2 \mathrm{~m}$ is a one-way slab

Although 2T10 bars in each rib at the bottom $\left(\mathrm{A}_{\mathrm{s}}\right.$ $=157 \mathrm{~mm}^{2}$ ) will be adequate to cater for the required steel area in the BS 8110 method for all the panels, the low analytical results from the use of BS 8110 coefficients may lead to under reinforcements of the ribs and hence allow for higher service stress in the steel provided. For the topping or slab portion, the use of $0.12 \mathrm{bh}$ gave the required area of steel to be $72 \mathrm{~mm}^{2}$ which was the minimum required, and a wire mesh D98 $\left(\mathrm{A}_{\mathrm{s}}=98 \mathrm{~mm}^{2}\right)$ can be provided.

If this is compared to the yield line analysis results, in the $6 \mathrm{~m} \times 6 \mathrm{~m}$ panel, the area of steel required was $771 \mathrm{~mm}^{2}$ with the provision of structural mesh B785 $\left(\mathrm{A}_{\mathrm{s}}=785 \mathrm{~mm}^{2}\right)$, for the $6 \mathrm{~m} \times 5 \mathrm{~m}$ panel the required steel area was 479 $\mathrm{mm}^{2}$ with the provision of structural mesh B503 ( $\mathrm{A}_{\mathrm{s}}=503 \mathrm{~mm}^{2}$ ), while the $5 \mathrm{~m} \times 2 \mathrm{~m}$ panel has the required steel area of $553 \mathrm{~mm}^{2}$ with provisional steel of long mesh C636 $\left(A_{s}=663 \mathrm{~mm}^{2}\right)$, the yield line method was able to analyse and provide adequate reinforcement for the type of eccentric loading that the slabs were to be subjected to during loading and transportation to the site instead of the minimum reinforcement from the BS 8110 method, the assumed value of minimum reinforcement is too small especially for large span panels, for example: the steel area required for the $5 \mathrm{~m} \mathrm{x} 2 \mathrm{~m}$ panel using minimum area of reinforcement was about $87 \%$ lower than the analysed results from YLRGT, this is a big disadvantage for the approximate method when the panel is subjected to eccentric forces in precast waffle slab panels.

The Yield line theory method was able to analyse the small slab portion because it is an upper bound theorem, the upper bound of the true collapse load is that external load for which the internal work done by the slab for a small increment of displacement is equal to the external work done by that external load for the same amount of small increment of displacement. The predicted failure load of a slab for given moment of resistance may be higher than or equal to the true value. However, it has been observed that the prediction of the most probable true mechanism in slab is not difficult. Thus, the solution in upper bound is safe and adequate in most of the cases. 
The area of steel required for the Yield line method are shown in Table 2, the least minimum area of reinforcement required in the short span ribs of the $6 \mathrm{~m} \times 6 \mathrm{~m}$ panel was $136 \mathrm{~mm}^{2}$, 2T10 $\left(A_{s}=157 \mathrm{~mm}^{2}\right)$ can be provided for both span, but for the $6 \mathrm{~m} \times 5 \mathrm{~m}$ panel with a required steel area of $238 \mathrm{~mm}^{2}$ in the short span rib, $4 \mathrm{~T} 10\left(\mathrm{~A}_{\mathrm{s}}\right.$ $=314 \mathrm{~mm}^{2}$ ) will be adequate to resist the load, while the required steel area for the $5 \mathrm{~m} \times 2 \mathrm{~m}$ short span rib was $179 \mathrm{~mm}^{2}$ and $3 \mathrm{~T} 10\left(\mathrm{~A}_{\mathrm{s}}=236\right.$ $\mathrm{mm}^{2}$ ) can be provided.

As discussed earlier, the reason for cracks and sometimes outright failures in the waffle slab panels was due to the use of wire mesh that cannot withstand the eccentric load from lifting cranes, transportation to site and eventual placements of the slabs to their positions on the site. The results obtained for the minimum reinforcements might be adequate for casting insitu waffle slabs that were not exposed to eccentric forces, but not for pre-cast waffle slabs that would be transported from the factory to the site and subjected to different types of loading conditions.

The reason for the cracks and failure in the precast slab of this research prototype was because the topping of the slab was subjected to both sagging and hogging moments during lifting. Since this portion of the slab was not designed to resist tensile moments (sagging / hogging), the forces generated as a result of lifting produced the tensile force that caused the slab topping to fail. The introduction of YLRGT is to complement the old system and to improve the load supporting action of precast waffle slabs, excessive loading as a results of lifting and transportation will always put the structural elements like steel reinforcements under serious stress as earlier observed, but the use of larger reinforcements area will reduce this stress to a minimum.

\section{Conclusions}

The study showed that one of the reasons for the failures observed in the precast waffle slabs was as a result of approximate analytical procedures adopted in the design and the provision of inadequate reinforcements at the slab portions while the ribs were sometimes under reinforced. YLRGT developed in this study for solving the problem was validated in the case study; by comparing the results of YLRGT analytical method with the results obtained from BS 8110 slab coefficient method, which many structural engineers have adopted in the analysis of waffle slab ribs. The results obtained showed good relationship between the two methods. However, the advantage of YLRGT over the BS 8110 method is the analysis of the slab portion separately using the Yield line theory and the rib portion by adopting the Rankine Grashoff theory in waffle slabs, the program can also be effectively used for the analysis of solid slabs. The introduction of YLRGT has facilitated the improved analysis of pre-cast waffle slabs. The use of YLRGT will enhance the structural integrity of pre-cast waffle slab as revealed when compared with the BS 8110 method. The program is safe and it is very easy to use.

\section{References}

[1] Prasad, J. Chander, S. and Ahuja, A.K. 'Optimum dimensions of waffle slabsfor medium size floors'. Asian Journal of Civil Engineering (Building and Housing) 2005. Vol.6, No.3 Pp 183-197.

[2] Daniel, A.S. and Onur, G. 'The design of William J.Clinton Presidential Centre'. The Civil Engineering Magazine,March 2005 edition.

[3] Buildings 'An Engineers guide to: Economical Concrete Floor Systems (IS063)'. Portland cement Association, Skokie IL, www.cement.org Retrieved March 2005.

[4]. Sadusky, K.M. "Pro-con Structural study of alternative floor system", Technical Assignment Journal No 2.2004

[5] Kenichi,I and Ai.S. "Collapse mechanism of the Windsor building by fire in Madrid and the plan for its demolition process". International Workshop on Emergency and Rescue. October31November1, 2005.

[6] Concrete center. "Waffle slab" http://www.concretecenter.com. Accessed June, 2006

[7] Krishna Raju, N. "Advanced reinforced concrete design". CBS Publishers, 485, Jain, Bhawan, Shahadra, Delhi. 1998.

[8] Howard, C.Q. and Hansen, C.H. "Vibration analysis of waffle floors". Unpublished, Department of Mechanical Engineering, University of Adelaide, South Australia. 2002

[9] Waffle-Crete International. "The multiple use of waffle-crete". www.waffle-crete.com. Accessed June 2009

[10] Abdel-Karim, R. and Mahmood , I.M.A." The effect of beams stiffnesses on the load distribution in a 
single simply supported two-way ribbed slab", The Islamic University Journal (series of Natural Studies and Engineering), Vol. 14, No.1, pp 191208, 2006

[11] Oyenuga,V.0. "Simplified reinforced concrete design," Astros Ltd, Surulere, Lagos, Nigeria. 2001

[12] British Standard Institution. "Structural Use of Concrete," BS 8110:Part 1. 1997, London.

[13] Mosley, W.H., Bungey, J.H. and Hulse. R. Reinforced concrete design, $5^{\text {th }}$ edition, Macmillan Education Limited, Houndmills, Basingstoke, Hampshire RG21 6XS. Pp207. 1999

[14] Rahman, M.K. Pillai, S.K.G and Baluch, M.H. "Strutand- tie model for waffle slabs". Advanced and trends in Structural Engineering, Mechanics and Computation. The proceeding of the $4^{\text {th }}$ International conference on Structural Engineering Mechanics and Computations, (SEMC 2010), Taylor and Francis Group, London. Pp 193.

[15] Carper, K.L. Current structural safety topics in North America. The Structural Engineer, Vol. 76, No. 12. pp 233-237. 1998.

[16] Kennedy, G and Goodchild, C.H,"Practical yield line design." The concrete centre, Riverside house, 4 Meadows Business Park, station approach, Camberly, Surrey. 2004 